\title{
EGFR and KRAS Mutations Predict the Incidence and Outcome of Brain Metastases in Non-Small Cell Lung Cancer
}

\author{
Pascale Tomasini ${ }^{1,2, *}$, Cindy Serdjebi ${ }^{1,3}$, Nataliya Khobta ${ }^{1}$, Philippe Metellus ${ }^{4}$, \\ L'Houcine Ouafik ${ }^{2,3}$, Isabelle Nanni ${ }^{3}$, Laurent Greillier ${ }^{1,2}$, Anderson Loundou ${ }^{5}$, \\ Frederic Fina $^{3}$, Celine Mascaux ${ }^{1,2}$ and Fabrice Barlesi ${ }^{1,2}$ \\ 1 Assistance Publique Hôpitaux de Marseille, Multidisciplinary Oncology \& Therapeutic Innovations \\ department. Aix Marseille University, Marseille 13015, France; cindy.serdjebi@univ-amu.fr (C.S.); \\ nataliyasantoni@hotmail.com (N.K.); laurent.greillier@ap-hm.fr (L.G.); celine.mascaux@ap-hm.fr (C.M.); \\ fabrice.barlesi@ap-hm.fr (F.B.) \\ 2 Inserm U911 CRO2 (Centre de Recherche en Oncologie biologique et Onco-pharmacologie), \\ Aix Marseille University, Marseille 13005, France; L'houcine.OUAFIK@ap-hm.fr \\ 3 Assistance Publique Hôpitaux de Marseille, Transfer Oncology Laboratory, Aix Marseille University, \\ Marseille 13015, France; Isabelle.NANNI@ap-hm.fr (I.N.); frederic.fina@ap-hm.fr (F.F.) \\ 4 Department of Neurosurgery, Aix-Marseille University, Marseille 13005, France; \\ philippe.metellus@outlook.fr \\ 5 Statistics Department, Aix Marseille University, Marseille 13005, France; anderson.loundou@univ-amu.fr \\ * Correspondence: pascale.tomasini@ap-hm.fr; Tel.: +33-491-965-901; Fax: +33-491-965-902
}

Academic Editor: Dario Marchetti

Received: 28 September 2016; Accepted: 7 December 2016; Published: 18 December 2016

\begin{abstract}
Background: Lung cancer is the leading cause of brain metastases (BM). The identification of driver oncogenes and matched targeted therapies has improved outcome in non-small cell lung cancer (NSCLC) patients; however, a better understanding of BM molecular biology is needed to further drive the process in this field. Methods: In this observational study, stage IV NSCLC patients tested for EGFR and KRAS mutations were selected, and BM incidence, recurrence and patients' outcome were assessed. Results: A total of 144 patients (142 Caucasian and two Asian) were selected, including $11.27 \%$ with EGFR-mutant and $33.10 \%$ with KRAS-mutant tumors, and $57.04 \%$ patients had developed BM. BM incidence was more frequent in patients with EGFR mutation according to multivariate analyses (MVA) (Odds ratio OR $=8.745$ [1.743-43.881], $p=0.008$ ). Among patients with treated $\mathrm{BM}$, recurrence after local treatment was less frequent in patients with KRAS mutation $(\mathrm{OR}=0.234$ [0.078-0.699], $p=0.009)$. Among patients with untreated $\mathrm{BM}$, overall survival (OS) was shorter for patients with KRAS mutation according to univariate analysis (OR $=7.130$ [1.240-41.012], $p=0.028)$, but not MVA. Conclusions: EGFR and KRAS mutations have a predictive role on BM incidence, recurrence and outcome in Caucasian NSCLC patients. These results may impact the routine management of disease in these patients. Further studies are required to assess the influence of other biomarkers on NSCLC BM.
\end{abstract}

Keywords: brain metastasis; lung neoplasm; KRAS; EGFR; incidence; recurrence; survival

\section{Introduction}

Lung cancer remains the leading cause of cancer-related deaths worldwide [1]. It is also the leading cause of brain metastases (BM), accounting for $40 \%$ to $50 \%$ of all $\mathrm{BM}$ [2]. In autopsy series, $\mathrm{BM}$ were found in approximately $50 \%$ lung cancer patients [3]. Moreover, BM are described as the primary or contributing cause of death in $50 \%$ of patients with BM from solid tumors [4]. Without any 
treatment, the median overall survival (OS) of lung cancer patients with BM is four to 11 weeks [4]. Local treatments such as neurosurgery, stereotactic radiosurgery (SRS) or whole brain radiation therapy (WBRT) improve local control and are associated with increased median OS of up to 14 months [5]. Furthermore, the combination of antiangiogenic therapies, such as bevacizumab, with chemotherapy increases the OS of patients with NSCLC BM. However, median OS does not exceed 16 months [6].

Over the past decade, advances have been made in the understanding of cancer biology [7]. EGFR mutations and ALK rearrangements are approved predictive biomarkers for advanced NSCLC targeted treatment. Advanced NSCLC with these genomic alterations can be targeted by tyrosine kinase inhibitors (TKI), including erlotinib [8], gefitinib [9], afatinib [10] or crizotinib [11] as a first line treatment. These therapies improved overall response rates (ORR), progression-free survival (PFS) and OS. Some of these therapies even demonstrated intra-cranial activity in retrospective sub-group analysis of large randomized phase III trials. Intracranial disease control rate (DCR) was 56\% (95\%, CI $46 \%-66 \%$ ) with crizotinib [12] and PFS was improved with afatinib relative to chemotherapy in patients with $\mathrm{BM}$ (8.2 versus 5.4 months, respectively; Hazard Ratio $(\mathrm{HR})=0.50 ; p=0.0297$ ) [13]. More recently, a phase II study of ceritinib in previously treated patients with ALK-rearranged NSCLC found an intracranial ORR of $45.0 \%$ (95\% CI, $23.1 \%$ to $68.5 \%$ ) among the 100 patients with baseline BM [14].

However, tumor genetic alterations are heterogeneous. Brain is considered to be a sanctuary site because of the blood-brain barrier (BBB). The BBB is a physiological obstruction to the delivery of systemic therapies to the brain parenchyma and central nervous system (CNS) [15] and it plays a key role in tumor cell migration and colonization to the brain [16]. For these reasons, there are large differences in biomarkers expressed between the primary tumor and metastases, especially for BM [17]. Overall, lung cancer BM biology is still poorly understood.

To develop new treatments for NSCLC patients with BM, an understanding of BM molecular biology is required. Driver mutations, growth factors and signaling pathways all seem to contribute to BM development [18]. Among lung cancer biomarkers, EGFR and KRAS are the most frequently mutated genes in lung cancer patients and have been routinely used as biomarkers for a decade.

We therefore conducted an observational study in an attempt to assess the role of KRAS and EGFR mutations in predicting BM incidence, recurrence as well as survival of NSCLC patients with BM.

\section{Results}

\subsection{Patient and Tumor Characteristics}

Data from a total of 144 patients tested for EGFR and KRAS mutations between January 2009 and December 2010 at MOTI were obtained. Among these patients, two were excluded because of mutations on both EGFR and KRAS genes. Out of the 142 remaining patients (48 females and 94 males), $140(98.59 \%)$ were Caucasian and two were Asian (1.41\%). Patient and disease characteristics are summarized in Table 1. With respect to metastatic status, 90 patients $(63.38 \%)$ had only one metastasis, 81 patients $(57.04 \%$ ) had BM and $64.2 \%$ of BM patients had synchronous BM.

Sixteen tumor samples (11.27\%) were positive for EGFR mutations (seven different types of EGFR mutation were found: one in exon 18, four in exon 19 and two in exon 21$)$ and 47 (33.10\%) tumor samples were positive for KRAS mutations (seven different types of KRAS mutations were found: five in codon 12 and two in codon 13). Of note, one tumor had two KRAS mutations (c.35G>A Gly12Asp; c.38G $>$ A Gly13Asp). The most frequent EGFR mutation was the Glu746_Ala750del exon 19 deletion $(50.00 \%)$, whereas Gly12Cys and Gly12Asp were the most frequent KRAS mutations $(72.34 \%)$. All mutations are described in Table S1.

A total of 125 patients $(88.03 \%)$ received a systemic treatment, of which a large proportion received chemotherapy $(80.28 \%$ ) relative to EGFR-tyrosine-kinase inhibitors ( $n=11,7.75 \%)$. Among the 81 patients with $\mathrm{BM}, 54.32 \%$ underwent surgery or stereotactic radiosurgery, while 21 patients $(25.93 \%)$ received whole brain radiation therapy (WBRT) only. The remaining patients did not receive any BM local treatment. Forty-one patients $(50.62 \%)$ had a BM recurrence after local treatment. 
Table 1. Patient and disease characteristics associated with mutation status. WT: wild type; F: female; M: male; ECOG PS: ECOG performance status; *: significant $p$-values $(p \leq 0.05)$.

\begin{tabular}{|c|c|c|c|c|c|}
\hline Characteristics & Total $n(\%)$ & $\begin{array}{c}\text { EGFR Mutant } \\
n(\%)\end{array}$ & $\begin{array}{c}\text { KRAS Mutant } \\
n(\%)\end{array}$ & $\begin{array}{c}E G F R \text { and } K R A S \\
\text { WT } n(\%)\end{array}$ & $p$-Value \\
\hline Overall $n(\%)$ & $142(100.00)$ & $16(11.27)$ & $47(33.10)$ & $79(55.63)$ & \\
\hline \multicolumn{6}{|c|}{ Patients' Characteristics } \\
\hline Median age (years) & $62(31-88)$ & $62(45-87)$ & $60(37-76)$ & $63(31-88)$ & \multirow{2}{*}{$\begin{array}{c}0.338 \\
0.46\end{array}$} \\
\hline Sex F/M & $48 / 94$ & $7 / 9$ & $16 / 31$ & $25 / 54$ & \\
\hline Ethnicity & & & & & \multirow{3}{*}{$0.006 *$} \\
\hline Caucasian & 140 (98.59) & $16(100.00)$ & $47(100.00)$ & 77 (97.47) & \\
\hline Asian & $2(1.41)$ & $0(0.00)$ & $0(0.00)$ & $2(2.53)$ & \\
\hline \multicolumn{6}{|l|}{ Smoking history } \\
\hline Smoker & $108(76.06)$ & $7(43.75)$ & $42(89.36)$ & $59(74.68)$ & \multirow[b]{2}{*}{$<0.001$ * } \\
\hline Non-smoker & $31(21.83)$ & $9(56.25)$ & $3(6.38)$ & $19(24.05)$ & \\
\hline \multicolumn{6}{|l|}{ ECOG PS } \\
\hline $0-1$ & $123(86.62)$ & $14(87.50)$ & $37(78.72)$ & $72(91.14)$ & \multirow{2}{*}{0.131} \\
\hline$\geq 2$ & $19(13.38)$ & $2(12.50)$ & $10(21.28)$ & $7(8.86)$ & \\
\hline \multirow{2}{*}{\multicolumn{6}{|c|}{$\begin{array}{c}\text { Disease Characteristics } \\
\text { Pathology }\end{array}$}} \\
\hline & & & & & \\
\hline Adenocarcinoma & 127 (89.44) & $14(87.50)$ & $46(97.87)$ & $67(84.81)$ & \multirow{2}{*}{0.050 * } \\
\hline Other & $15(10.56)$ & $2(12.50)$ & $1(2.13)$ & $12(15.19)$ & \\
\hline \multicolumn{6}{|l|}{ Number of metastases } \\
\hline 1 & $90(63.38)$ & $10(62.50)$ & $27(57.45)$ & $53(67.09)$ & \multirow{2}{*}{0.553} \\
\hline$\geq 2$ & $52(36.62)$ & $6(37.50)$ & $20(42.55)$ & $26(32.91)$ & \\
\hline
\end{tabular}

\subsection{Association between Mutation Status and Brain Metastases (BM) Incidence and Recurrence}

BM incidence was more frequent in patients with EGFR-mutant $(87.50 \%)$ than in patients with KRAS-mutant (55.32\%) or double WT tumors (51.90\%, $p=0.031$, Table 2$)$. While no difference was seen in BM incidence according to age $(p=0.799)$, sex $(p=0.621)$, ECOG PS $(p=0.936)$, smoking status $(p=0.515)$ or primary tumor local treatment $(p=0.498)$, a higher frequency of BM was observed in patients with EGFR-mutant compared to KRAS-mutant and double WT tumors in univariate analyses (Odds Ratio OR $=6.488,95 \%$ confidence interval CI [1.383-30.443], $p=0.018$ ) (Table 3) and confirmed in multivariate analysis (OR $=8.745,95 \% \mathrm{CI}$ [1.743-43.881], $p=0.008$ ) (Table 3).

$\mathrm{BM}$ recurrence after any local treatment was less frequent in patients with KRAS-mutant $(30.77 \%)$ than in patients with EGFR-mutant $(57.14 \%)$ or in double WT tumors $(60.98 \%, p=0.047$, Table 2$)$. While no difference was seen in BM recurrence according to age $(p=0.562)$, sex $(p=0.939)$, ECOG PS $(p=0.315)$, smoking status $(p=0.911)$ or BM local treatment $(p=0.709)$ (Table 3$)$, the lower frequency of BM recurrence was confirmed in patients with KRAS-mutant compared to EGFR-mutant and double WT tumors in univariate analyses $(\mathrm{OR}=0.284,95 \% \mathrm{CI}[0.100-0.807], p=0.018)$ (Table 3 ) and confirmed in multivariate analysis ( $\mathrm{OR}=0.234,95 \% \mathrm{CI}[0.078-0.699], p=0.009)$ (Table 3). 
Table 2. Association between mutation status and brain metastasis incidence and recurrence. WT: wild type; BM: brain metastases; *: significant $p$-value.

\begin{tabular}{|c|c|c|c|c|c|}
\hline BM Characteristics & Total $n(\%)$ & $\begin{array}{c}\text { EGFR Mutant } \\
n(\%)\end{array}$ & $\begin{array}{c}\text { KRAS Mutant } \\
n(\%)\end{array}$ & $\begin{array}{c}E G F R \text { and } K R A S \\
\text { WT } n(\%)\end{array}$ & $p$-Value \\
\hline \multicolumn{6}{|c|}{ BM Incidence } \\
\hline \multicolumn{6}{|l|}{ Brain Metastasis } \\
\hline Yes & $81(57.04)$ & $14(87.50)$ & $26(55.32)$ & $41(51.90)$ & \multirow{2}{*}{0.031 * } \\
\hline No & $61(42.96)$ & $2(12.50)$ & $21(44.68)$ & $38(48.10)$ & \\
\hline Synchronous & $52(64.20)$ & $8(57.14)$ & $18(69.23)$ & $26(63.41)$ & \multirow[b]{2}{*}{0.741} \\
\hline Metachronous & $29(35.80)$ & $6(42.86)$ & $8(30.77)$ & $15(26.59)$ & \\
\hline \multicolumn{6}{|c|}{ Brain Metastasis Related Death } \\
\hline Yes & $31(42.26)$ & $7(50.00)$ & $11(44.00)$ & $13(34.21)$ & \multirow{2}{*}{0.528} \\
\hline No & $46(59.74)$ & $7(50.00)$ & $14(56.00)$ & $25(65.79)$ & \\
\hline \multicolumn{6}{|c|}{ BM Recurrence } \\
\hline \multicolumn{6}{|l|}{ Recurrence } \\
\hline Yes $n(\%)$ & $41(50.62)$ & $8(57.14)$ & $8(30.77)$ & $25(60.98)$ & \multirow{2}{*}{$0.047^{*}$} \\
\hline No $n(\%)$ & $40(49.38)$ & $6(42.86)$ & $18(69.23)$ & $16(39.02)$ & \\
\hline \multicolumn{6}{|l|}{ Time to Recurrence } \\
\hline$\leq 12$ months $n(\%)$ & $29(70.73)$ & $6(75.00)$ & $6(75.00)$ & $17(68.00)$ & \multirow{2}{*}{1.000} \\
\hline$>12$ months $n(\%)$ & $12(29.27)$ & $2(25.00)$ & $2(25.00)$ & $8(32.00)$ & \\
\hline
\end{tabular}

Table 3. Univariate and multivariate analyses of BM incidence and recurrence. OR: odds ratio; $95 \%$ CI: $95 \%$ confidence interval; BM: brain metastasis; age: $<65$ versus $\geq 65$; sex female versus male; ethnicity: Caucasian versus non Caucasian; smoking status: smoker versus non-smoker; primitive tumor local treatment: surgery or radiation therapy versus no local treatment; Mutation status: EGFR-mutant versus KRAS-mutant versus KRAS and EGFR wild-type tumors; WT: wild-type; BM local treatment: any local treatment (whole brain radiation therapy, surgery or radiosurgery) versus no local treatment; number of metastases: one metastasis versus several metastases; NA: not applicable; *: significant $p$-value.

\begin{tabular}{|c|c|c|c|c|c|c|}
\hline \multirow{2}{*}{ Characteristics } & \multicolumn{3}{|c|}{ Univariate Analyses } & \multicolumn{3}{|c|}{ Multivariate Analyses } \\
\hline & OR & $95 \% \mathrm{CI}$ & $p$-Value & OR & $95 \% \mathrm{CI}$ & $p$-Value \\
\hline \multicolumn{7}{|l|}{ BM Incidence } \\
\hline Age & 0.996 & $0.965-1.027$ & 0.799 & 0.998 & $0.965-1.032$ & 0.897 \\
\hline Sex & 1.193 & $0.592-2.404$ & 0.621 & 0.988 & $0.440-2.219$ & 0.977 \\
\hline ECOG PS & 1.041 & $0.391-2.769$ & 0.936 & NA & NA & NA \\
\hline Smoking status & 0.767 & $0.345-1.706$ & 0.515 & 0.489 & $0.178-1.339$ & 0.164 \\
\hline Primary tumor local treatment & 1.384 & $0.541-3.545$ & 0.498 & NA & NA & NA \\
\hline Mutation status & & & 0.060 & & & $0.031 *$ \\
\hline EGFR mutant versus EGFR WT & 6.488 & $1.383-30.443$ & $0.018 *$ & 8.745 & $1.743-43.881$ & $0.008 *$ \\
\hline KRAS mutant versus KRAS WT & 1.148 & $0.556-2.369$ & 0.710 & 1.082 & $0.505-2.318$ & 0.840 \\
\hline \multicolumn{7}{|l|}{ BM Recurrence after Local Treatment } \\
\hline Age & 0.987 & $0.944-1.032$ & 0.562 & 0.975 & $0.929-1.023$ & 0.296 \\
\hline Sex & 1.037 & $0.408-2.636$ & 0.939 & 0.983 & $0.322-3.000$ & 0.976 \\
\hline ECOG PS & 0.510 & $0.137-1.898$ & 0.315 & NA & NA & NA \\
\hline Smoking status & 0.939 & $0.314-2.810$ & 0.911 & 0.626 & $0.153-2.565$ & 0.515 \\
\hline Mutation status & & & 0.054 & & & $0.029 *$ \\
\hline EGFR mutant versus EGFR WT & 0.853 & $0.249-2.921$ & 0.801 & 0.970 & $0.245-3.845$ & 0.966 \\
\hline KRAS mutant versus KRAS WT & 0.284 & $0.100-0.807$ & 0.018 * & 0.234 & $0.078-0.699$ & $0.009 *$ \\
\hline Synchronous or metachronous BM & 1.786 & $0.712-4.480$ & 0.216 & NA & NA & NA \\
\hline BM local treatment & 0.709 & $0.236-2.133$ & 0.541 & NA & NA & NA \\
\hline Number of metastases & 0.962 & $0.390-2.370$ & 0.932 & NA & NA & NA \\
\hline
\end{tabular}

\subsection{Association between Mutations Status, BM and Survival}

In the overall population, mutation status was not associated with OS: OS was 22, 9 and 18 months respectively for patients with EGFR-mutant, KRAS-mutant or double WT tumors, respectively $(p=0.196)$ (Table 4). 
In the subgroup of patients with treated BM, mutation status had no impact on PFS ( $p=0.227$ for surgery and/or SRS; $p=0.272$ for WBRT only) and OS ( $p=0.822$ for surgery and/or SRS; $p=0.208$ for WBRT only) (Table 4).

In the subgroup of patients with untreated BM, mutation status was not associated with PFS (PFS for EGFR-mutant, KRAS-mutant or double WT tumors was 10, 5 and 6 months, respectively, $p=0.229$ ). However, OS was significantly less in patients with KRAS-mutant (5 months) in comparison with patients with EGFR-mutant (19 months) and double WT tumors (14 months, $p=0.010$ ) (Table 4). In addition, the number of metastases $(p=0.003)$ and ECOG PS $(p=0.011)$ were significantly associated with OS in univariate analysis ( $p=0.010$ ) (Table 5$)$. In this subgroup of patients with untreated BM, multivariate analyses did not confirm the association between KRAS mutation and OS $(\mathrm{OR}=0.356$, 95\%CI [0.015-8.224], $p=0.519$ ) (Table 5).

Table 4. Association between mutation status and survival. OS and PFS and mutation status in all patients and in patients with BM segregated into two groups. WT: wild type; PFS: progression free survival; OS: overall survival; SRS: stereotactic radio-surgery; WBRT; whole brain radiation therapy; *: significant $p$-value.

\begin{tabular}{|c|c|c|c|c|}
\hline Population & EGFR Mutant & KRAS Mutant & $E G F R$ and $K R A S \mathrm{WT}$ & $p$-Value \\
\hline \multicolumn{5}{|c|}{ PFS and OS } \\
\hline All patients $n(\%)$ & $16(11.27)$ & $47(33.10)$ & $79(55.63)$ & \multirow{2}{*}{0.196} \\
\hline Median OS (months) & $22(4.36-39.64)$ & $9(7.12-10.88)$ & $18(12.30-23.70)$ & \\
\hline Patients with BM $n(\%)$ & $14(17.28)$ & $26(32.10)$ & $41(50.62)$ & \\
\hline Surgery and/or SRS & & & & \\
\hline Median PFS (months) & $7(6.12-7.88)$ & $9(5.67-12.33)$ & $8(5.08-9.16)$ & 0.227 \\
\hline Median OS (months) & $30(4.24-55.77)$ & $22(7.58-36.42)$ & $25(20.44-29.56)$ & 0.822 \\
\hline \multicolumn{5}{|l|}{ WBRT only } \\
\hline Median PFS (months) & $11(0.00-23.88)$ & $9(1.30-16.70)$ & $6(5.08-6.92)$ & 0.272 \\
\hline Median OS (months) & $28(0.00-73.09)$ & $7(1.87-12.13)$ & $12(5.36-18.65)$ & 0.208 \\
\hline \multicolumn{5}{|l|}{ No local treatment } \\
\hline Median PFS (months) & $10(8.40-11.60)$ & $5(1.80-8.20)$ & $6(3.23-8.77)$ & 0.229 \\
\hline Median OS (months) & $19(1.85-36.15)$ & $5(0.00-12.85)$ & $14(12.22-14.78)$ & 0.010 * \\
\hline
\end{tabular}

Table 5. Univariate and multivariate analyses of overall survival in patients with untreated brain metastasis. OR: odds ratio; 95\% CI: 95\% confidence interval; BM: brain metastasis; age: $<65$ versus $\geq 65$; sex female versus male; ethnicity: Caucasian versus non-Caucasian; smoking status: smoker versus nonsmoker; primary tumor local treatment: surgery or radiation therapy versus no local treatment; Mutation status: EGFR mutant versus KRAS mutant versus KRAS and EGFR wild type tumors; WT: wild-type; number of metastases: one metastasis versus several metastases; *: significant $p$-value.

\begin{tabular}{|c|c|c|c|c|c|c|}
\hline \multirow{2}{*}{ Characteristics } & \multicolumn{3}{|c|}{ Univariate Analyses } & \multicolumn{3}{|c|}{ Multivariate Analyses } \\
\hline & OR & $95 \% \mathrm{CI}$ & $p$-Value & OR & $95 \% \mathrm{CI}$ & $p$-Value \\
\hline \multicolumn{7}{|l|}{ OS of Patients with Untreated BM } \\
\hline Age & 1.018 & $0.968-1.071$ & 0.484 & NA & NA & NA \\
\hline Sex & 1.41 & $0.310-6.044$ & 0.657 & NA & NA & NA \\
\hline ECOG PS & 8.366 & $1.643-42.606$ & 0.011 * & 8.768 & $0.493-155.954$ & 0.139 \\
\hline Smoking status & 0.951 & $0.203-4.449$ & 0.949 & NA & NA & NA \\
\hline Mutation status & & & $0.010 *$ & & & 0.698 \\
\hline EGFR mutant versus EGFR WT & 0.536 & $0.136-2.115$ & 0.374 & 0.589 & $0.134-2.581$ & 0.482 \\
\hline$K R A S$ mutant versus KRAS WT & 7.130 & $1.240-41.012$ & $0.028 *$ & 0.356 & $0.015-8.224$ & 0.519 \\
\hline Synchronous or metachronous BM & 1.017 & $0.339-3.047$ & 0.976 & NA & NA & NA \\
\hline Number of metastases & 11.548 & $2236-59.640$ & $0.003 *$ & 6.669 & $1.022-43.541$ & $0.047 *$ \\
\hline
\end{tabular}




\section{Discussion}

We analyzed the association of KRAS and EGFR mutations with brain metastases incidence, recurrence and prognosis in a population of patients with metastatic NSCLC. We observed a higher incidence of BM in patients with EGFR-mutant tumors in comparison with KRAS-mutant and wild type tumors, independent of systemic treatment or primary lung tumor local treatment. Additionally, although KRAS-mutant tumors are considered to be more aggressive tumors [19], we found a lower rate of $\mathrm{BM}$ recurrence after local treatment for patients with KRAS-mutant relative to EGFR-mutant and wild-type tumors. Despite the lower BM incidence and the better control of BM after local treatment in the KRAS-mutant group, these patients had a shorter overall survival. This suggests that the poor prognosis of KRAS-mutant NSCLC does not rely on BM. Conversely, despite having a higher incidence of BM, patients with EGFR-mutant NSCLC have a better prognosis.

The population studied was a homogeneous population of stage IV non-squamous NSCLC patients, representative of other European cohorts, with a very large majority of Caucasian patients. The frequency of KRAS-mutant (34\%) and EGFR-mutant (12.5\%) tumors was indeed similar that observed in other Caucasian populations of advanced NSCLC patients [20,21]. Furthermore, we analyzed data not only from patients enrolled in clinical trials, but also from all patients diagnosed in routine practice. For this reason, the population studied here is more representative of NSCLC patient than other studies where stringent exclusion criteria were applied.

Because of the high incidence (approximately $50 \%$ of advanced lung cancer patients [3]) and contribution to mortality [4], of BM, a better characterization of the molecular profile associated with BM incidence and prognosis in NSCLC patients was needed. While a positive correlation of EGFR mutations with BM is commonly admitted, this is, to our knowledge, the first study to report it in a population of Caucasian patients with advanced NSCLC. These clinically relevant results suggest that patients with EGFR-mutant tumors should be carefully monitored for early detection of BM development.

Several case series, reported in Table 6, assess the association of molecular profile with NSCLC BM. However, these series predicted conflicting results due to disparities in the specific types of lung cancer studied, including both squamous and non-squamous and both advanced and early-stage NSCLC. Shin et al. [22] and Guan et al. [23] revealed a positive correlation between EGFR mutations and BM. More recently, Baek et al. [24] reported that BM were more frequent in NSCLC patients with EGFR-mutant $(27.4 \%)$ compared to EGFR wild type tumors $(14.5 \%, p<0.009)$ in a cohort of 259 patients with advanced NSCLC. However, these studies were performed in Asian populations. One report demonstrated a positive correlation between EGFR mutations and BM in a Caucasian population but it was performed in patients with resected early-stage lung cancer and metastatic recurrence [25].

Other studies found no correlation between BM and molecular profile. For example, Hendricks et al. [26] noted no difference in BM incidence between NSCLC patients with EGFR-mutant, KRAS-mutant or double wild-type tumors $(p=0.645)$. This is likely due to the design of this controlled study: they enrolled the same number of patients in the three groups, whereas we enrolled all patients diagnosed with advanced NSCLC who underwent prospective molecular testing. Therefore, our study is more representative of stage IV NSCLC patients. In the same way, Li et al. [27] found no relationship between mutation status and BM incidence; however, in this study, biomarkers were analyzed from patient serum instead of tissue, which is a much less sensitive technique. Another study of 100 Asian patients with EGFR mutations and BM did not find any difference in the general population but identified a significantly higher incidence of BM for patients with EGFR exon 19 deletions $(p=0.007$ ) [28]. This positive correlation between EGFR exon 19 deletion and BM has been previously reported [29] but we did not find any difference of BM incidence according to the EGFR mutation subtype in our study $(p=0.072)$.

Regarding the correlation between mutation profile and BM prognosis, Shin et al. demonstrated that patients with EGFR-mutant NSCLC underwent salvage therapy after stereotactic radiosurgery more often than patients with EGFR wild-type tumors ( $p=0.04)$ [30]. Other studies found molecular 
profile to be an independent prognostic factor for patients with NSCLC BM. Li et al. noted that EGFR exon 19 deletions were associated with a better prognosis $(p=0.034)$ in a population of 106 patients with BM from NSCLC [31]. These results are consistent with ours and suggest that EGFR mutations remain a good prognostic factor even if they are associated with a higher rate of BM relapse after local treatment.

Table 6. Case series assessing the association of molecular profile with NSCLC BM. NSCLC = non-small cell lung cancer, $\mathrm{ADC}=$ adenocarcinoma, $\mathrm{BM}=$ brain metastases, $\mathrm{NA}=$ not applicable.

\begin{tabular}{|c|c|c|c|c|c|}
\hline References & $\begin{array}{l}\text { Patients } \\
\text { Number }\end{array}$ & Ethnicity & Pathology & NSCLC Stage & Results \\
\hline$[22]$ & 314 & Asian & $\mathrm{ADC}$ & All & $\begin{array}{l}\text { Association between } E G F R \text { mutation } \\
\text { and BM incidence }\end{array}$ \\
\hline [23] & 401 & Asian & NSCLC & All & $\begin{array}{l}\text { Association between EGFR mutation } \\
\text { and BM incidence }\end{array}$ \\
\hline$[24]$ & 259 & Asian & NSCLC & Advanced & $\begin{array}{l}\text { Association between EGFR mutation } \\
\text { and synchronous BM and longer } \\
\text { median BM-OS }\end{array}$ \\
\hline [25] & 481 & Caucasian & NSCLC & Early & $\begin{array}{l}\text { EGFR mutations predict } \mathrm{BM}, K R A S \\
\text { mutations predict } \\
\text { pleuro-pericardial metastases }\end{array}$ \\
\hline [26] & 189 & Caucasian & NSCLC & All & $\begin{array}{l}\text { No association between EGFR and } K R A S \\
\text { mutation status and BM incidence }\end{array}$ \\
\hline [27] & 118 & NA & NSCLC & IV & $\begin{array}{l}\text { No association between EGFR mutation } \\
\text { status and BM incidence }\end{array}$ \\
\hline [28] & 100 & Asian & EGFR-mutant ADC & All & $\begin{array}{l}\text { Association between EGFR exon } 19 \\
\text { deletion and BM incidence }\end{array}$ \\
\hline [29] & 55 & Caucasian & $\begin{array}{l}\text { EGFR-mutant } \\
\text { NSCLC }\end{array}$ & All & $\begin{array}{l}\text { Association between EGFR exon } 19 \\
\text { deletion and BM incidence }\end{array}$ \\
\hline [30] & 236 & NA & NSCLC & IV (BM) & $\begin{array}{l}\text { Patients with EGFR mutant BM had } \\
\text { improved survival }\end{array}$ \\
\hline$[31]$ & 106 & Asian & NSCLC & IV (BM) & $\begin{array}{l}\text { Exon } 19 \text { deletion is an independent } \\
\text { prognostic factor in BM from NSCLC }\end{array}$ \\
\hline
\end{tabular}

Finally, whereas EGFR was proven to be involved in tumor tissue self-renewal and metastasis, no previously published biological or preclinical data could be identified to explain the propensity of EGFR-mutant NSCLC to develop BM and this remains to be explored [32]. Indeed, cancer invasiveness is stimulated by numerous mechanisms, including activating EGFR mutations [33]. Furthermore, a recent meta-analysis by Wang and Wang [34] exploring the correlation of EGFR status between primary tumors and metastases revealed that EGFR mutations should occur before metastasis, suggesting that $E G F R$ mutations play a role in this process.

The main limitation of this study is its retrospective design. In addition, the population analyzed is relatively old since patients were diagnosed with advanced NSCLC from 2009 to 2011. However, this population was chosen to obtain mature OS data and to improve the homogeneity in terms of systemic therapies.

Future investigations are needed to elucidate the biological mechanisms underlying the association between EGFR mutation and higher rate of BM development in NSCLC patients. Furthermore, it will be important to assess how these results will impact treatment and follow-up of patients with EGFR-mutant NSCLC. Potential impact include an increase in the implementation of brain imaging evaluations with brain MRI (magnetic resonance imaging) or the use of new EGFR-TKIs with a better BBB penetration. A preclinical study recently revealed that osimertinib was a better option than gefitinib, rociletinib or afatinib for EGFR-mutant NSCLC and brain metastases, with a greater brain exposure and BBB penetration [35]. Finally, in this study, we focused on EGFR and KRAS mutations. However, other biomarkers may be associated with NSCLC BM incidence or prognosis. For example, $A L K$ rearrangement has also been described as a risk factor for BM development [36]. For this reason, we plan to conduct a study of NSCLC BM biomarkers including whole exome data. 


\section{Experimental Section}

\subsection{Patients and Data Collection}

Patients diagnosed at the Multidisciplinary Oncology and Therapeutic Innovations department (MOTI) of Aix Marseille University Hospital from January 2009 to December 2010 with metastatic non-squamous non-small cell lung cancer (ns-NSCLC) were included. In this study, inclusion criteria were the following: ns-NSCLC, stage IV at diagnosis, age above 18 years, and EGFR and KRAS mutations testing. Exclusion criteria were squamous cell carcinoma and/or no molecular testing. Patients with both EGFR and KRAS mutant tumors were also excluded this is an uncommon molecular profile that could not have been analyzed separately because of the small size $(n=2)$ of this population and would have induced statistical bias if they were analyzed twice with the other groups of patients with a single mutation.

Disease stage was assessed using the 7th IASCL (International Association for the Study of Lung Cancer) TNM classification [37]. Treatment efficacy was assessed using RECIST 1.1 (Response Evaluation Criteria in Solid Tumors) criteria [38]. Demographics (age, sex, ethnicity), clinical characteristics (ECOG performance status, smoking history, disease stage and metastases localization), biological characteristics (pathology, and EGFR and KRAS mutation status), treatment and survival outcomes were retrieved from the electronic patients' records. BM was considered as synchronous if discovered at the time of NSCLC diagnosis and metachronous if discovered on later evaluation imaging.

This study was approved by a national ethics committee (CEPRO, Comité d'Evaluation des Protocoles de Recherche Observationnelle, reference number 2015-041), according to French law.

\subsection{Molecular Testing}

EGFR and KRAS mutations were analyzed for each patient from formalin-fixed, paraffin-embedded tissue, either from the primary tumor, lymph node or metastasis.

\subsubsection{Pre-analytical Stage}

Serial $4 \mu \mathrm{m}$-thick sections prepared from paraffin-embedded tumor samples were dissected. Genomic DNA was extracted using NucleoSpin ${ }^{\circledR} 96$ DNA blood kit (Macherey-Nagel, Düren, Germany) according to the manufacturer's protocol. DNA elution was carried out in $200 \mu \mathrm{L}$ of bovine serum albumin at $0.5 \mathrm{mg} / \mathrm{mL}$. DNA was stored at $-20{ }^{\circ} \mathrm{C}$ until use.

\subsubsection{High Resolution Melting (HRM)}

PCR amplification and HRM analysis from genomic DNA were carried out on LightCycler ${ }^{\circledR} 480$ (Roche Diagnostics, Meylan, France). Amplification consisted on $10 \mathrm{~min}$ at $95^{\circ} \mathrm{C}$, followed by 40 cycles of $10 \mathrm{~s}$ at $95^{\circ} \mathrm{C}$ and $20 \mathrm{~s}$ at 65 and $50{ }^{\circ} \mathrm{C}$ for EGFR and $K R A S$, respectively, and $30 \mathrm{~s}$ at $72{ }^{\circ} \mathrm{C}$ for elongation. PCR was then carried out on LightCycler ${ }^{\circledR} 480$. Mutant cell lines, wild-type DNA (placenta), and PCR negative controls were included together with patient samples. Temperature ramping (from 60 to $95^{\circ} \mathrm{C}$, rising by $0.02{ }^{\circ} \mathrm{C} / \mathrm{s}$ ) and fluorescence acquisition settings were recommended by the manufacturer. HRM curves were normalized for each sample, and compared with wild-type genomic DNA using LightCycler ${ }^{\circledR} 480$ gene-scanning software [39].

\subsection{Sequencing}

Sanger sequencing was performed only for samples defined as "abnormal" after qPCR-HRM, using Big Dye Terminator v3.1 cycle sequencing kit (Life Technologies, Villebon-sur-Yvette, France) after DNA purification (ExoSap-IT ${ }^{\circledR}$ ), on Evo75 ${ }^{\circledR}$ (Tecan, Männedorf, Switzerland). Sequences were analyzed on 3500 or 3130 Dx Genetic Analyser ${ }^{\circledR}$ (Applied Biosystems, Villebon-sur-Yvette, France). 


\subsection{Treatment}

Systemic treatment was decided after an MTB (Molecular Tumor Board) discussion on the basis of the ASCO (American Society of Clinical Oncology) [40] and ESMO (European Society of Medical Oncology) guidelines [41]. Local BM treatment was decided after Multidisciplinary Tumor Board discussion according to European and French guidelines [42,43].

\subsection{Statistical Analysis}

Statistical analysis was performed using IBM SPSS Statistics for Windows, Version 20.0 (IBM SPSS Inc., Chicago, IL, United States of America (USA)). Continuous variables were expressed as the mean \pm standard deviation (SD) or as median with range (min, max), and categorical variables were reported as count and percentages. Comparisons of mean values between two groups were performed using Student's $t$-test or Mann-Whitney $U$ test. Comparisons of percentages were performed using Chi-Square test or Fisher's exact test, as appropriate. Independent-sample $t$-tests and one-way analysis of variance were used to compare continuous variables between more than two groups. Time-to-event endpoints were estimated by the Kaplan-Meier method and compared using the log-rank test. OS was defined as the time from diagnosis to death from any cause, censored at the date of last follow-up. PFS was defined as the time from the beginning of treatment to documented progression or death, censored at the date of the last documented disease evaluation. Medians were reported with $95 \%$ confidence interval. Univariate and multivariate Cox proportional hazard regression models were used to estimate the HR. Multivariate analyses were performed when $p<0.2$ or for clinically relevant parameters. For all the tests, a $p$-value $<0.05$ was considered significant.

\section{Conclusions}

This is the first study reporting the predictive role of EGFR and KRAS mutations on BM incidence, recurrence and patients' outcomes in a Caucasian cohort of NSCLC patients. EGFR mutations are predictive for a higher incidence of $\mathrm{BM}$ while KRAS mutations are predictive for a lower rate of $\mathrm{BM}$ recurrence after local treatment and shorter survival. These results have to be validated in further studies and potentially. However, they already impact the routine management of NSCLC patients, highlignting the need for an increase in the implementation of brain imaging evaluations with brain MRI or the use of new EGFR-TKIs with a better BBB penetration.

Supplementary Materials: Supplementary materials can be found at www.mdpi.com/1422-0067/17/12/2132/s1.

Author Contributions: Pascale Tomasini, Philippe Metellus and Fabrice Barlesi conceived and designed the experiments; Nataliya Khobta, L'Houcine Ouafik, Isabelle Nanni and Frederic Fina performed the experiments; Laurent Greillier, Anderson Loundou, Frederic Fina and Celine Mascaux analyzed the data; Pascale Tomasini, Cindy Serdjebi and Celine Mascaux wrote the paper.

Conflicts of Interest: The authors declare no conflict of interest.

\section{References}

1. Torre, L.A.; Bray, F.; Siegel, R.L.; Ferlay, J.; Lortet-Tieulent, J.; Jemal, A. Global cancer statistics, 2012. CA Cancer J. Clin. 2015, 65, 87-108. [CrossRef] [PubMed]

2. Nussbaum, E.S.; Djalilian, H.R.; Cho, K.H.; Hall, W.A. Brain metastases. Histology, multiplicity, surgery, and survival. Cancer 1996, 78, 1781-1788. [CrossRef]

3. Taillibert, S.; Le Rhun, É. Epidemiology of brain metastases. Cancer Radiother. 2015, 19, 3-9. [CrossRef] [PubMed]

4. Zimm, S.; Wampler, G.L.; Stablein, D.; Hazra, T.; Young, H.F. Intracerebral metastases in solid-tumor patients: Natural history and results of treatment. Cancer 1981, 48, 384-394. [CrossRef]

5. Won, Y.K.; Lee, J.Y.; Kang, Y.N.; Jang, J.S.; Kang, J.-H.; Jung, S.-L.; Sung, S.Y.; Jo, I.Y.; Park, H.H.; Lee, D.-S.; et al. Stereotactic radiosurgery for brain metastasis in non-small cell lung cancer. Radiat. Oncol. J. 2015, 33, 207-216. [CrossRef] [PubMed] 
6. Besse, B.; Le Moulec, S.; Mazières, J.; Senellart, H.; Barlesi, F.; Chouaid, C.; Dansin, E.; Bérard, H.; Falchero, L.; Gervais, R.; et al. Bevacizumab in Patients with Nonsquamous Non-Small Cell Lung Cancer and Asymptomatic, Untreated Brain Metastases (BRAIN): A Nonrandomized, Phase II Study. Clin. Cancer Res. 2015, 21, 1896-1903. [CrossRef] [PubMed]

7. Hanahan, D.; Weinberg, R.A. Hallmarks of cancer: The next generation. Cell 2011, 144, 646-674. [CrossRef] [PubMed]

8. Rosell, R.; Carcereny, E.; Gervais, R.; Vergnenegre, A.; Massuti, B.; Felip, E.; Palmero, R.; Garcia-Gomez, R.; Pallares, C.; Sanchez, J.M.; et al. Spanish Lung Cancer Group in collaboration with Groupe Français de Pneumo-Cancérologie and Associazione Italiana Oncologia Toracica Erlotinib versus standard chemotherapy as first-line treatment for European patients with advanced EGFR mutation-positive non-small-cell lung cancer (EURTAC): A multicentre, open-label, randomised phase 3 trial. Lancet Oncol. 2012, 13, 239-246. [PubMed]

9. Mok, T.S.; Wu, Y.-L.; Thongprasert, S.; Yang, C.-H.; Chu, D.-T.; Saijo, N.; Sunpaweravong, P.; Han, B.; Margono, B.; Ichinose, Y.; et al. Gefitinib or carboplatin-paclitaxel in pulmonary adenocarcinoma. N. Engl. J. Med. 2009, 361, 947-957. [CrossRef] [PubMed]

10. Sequist, L.V.; Yang, J.C.-H.; Yamamoto, N.; O’Byrne, K.; Hirsh, V.; Mok, T.; Geater, S.L.; Orlov, S.; Tsai, C.-M.; Boyer, M.; et al. Phase III study of afatinib or cisplatin plus pemetrexed in patients with metastatic lung adenocarcinoma with EGFR mutations. J. Clin. Oncol. 2013, 31, 3327-3334. [CrossRef] [PubMed]

11. Shaw, A.T.; Kim, D.-W.; Nakagawa, K.; Seto, T.; Crinó, L.; Ahn, M.-J.; de Pas, T.; Besse, B.; Solomon, B.J.; Blackhall, F.; et al. Crizotinib versus chemotherapy in advanced ALK-positive lung cancer. N. Engl. J. Med. 2013, 368, 2385-2394. [CrossRef] [PubMed]

12. Costa, D.B.; Shaw, A.T.; Ou, S.-H.I.; Solomon, B.J.; Riely, G.J.; Ahn, M.-J.; Zhou, C.; Shreeve, S.M.; Selaru, P.; Polli, A.; et al. Clinical experience with crizotinib in patients with advanced ALK-rearranged non-small-cell lung cancer and brain metastases. J. Clin. Oncol. 2015, 33, 1881-1888. [CrossRef] [PubMed]

13. Schuler, M.; Wu, Y.-L.; Hirsh, V.; O’Byrne, K.; Yamamoto, N.; Mok, T.; Popat, S.; Sequist, L.V.; Massey, D.; Zazulina, V.; et al. First-line afatinib versus chemotherapy in patients with non-small cell lung cancer and common epidermal growth factor receptor gene mutations and brain metastases. J. Thorac. Oncol. 2016, 11, 380-390. [CrossRef] [PubMed]

14. Crinò, L.; Ahn, M.-J.; De Marinis, F.; Groen, H.J.M.; Wakelee, H.; Hida, T.; Mok, T.; Spigel, D.; Felip, E.; Nishio, M.; et al. Multicenter phase II study of whole-body and intracranial activity with ceritinib in patients with ALK-rearranged non-small-cell lung cancer previously treated with chemotherapy and crizotinib: Results from ASCEND-2. J. Clin. Oncol. 2016, 34, 2866-2873. [CrossRef] [PubMed]

15. Deeken, J.F.; Löscher, W. The blood-brain barrier and cancer: Transporters, treatment, and Trojan horses. Clin. Cancer Res. 2007, 13, 1663-1674. [CrossRef] [PubMed]

16. Wrobel, J.K.; Toborek, M. Blood-brain barrier remodeling during brain metastasis formation. Mol. Med. Camb. Mass 2016, 22, 32-40. [CrossRef] [PubMed]

17. Gomez-Roca, C.; Raynaud, C.M.; Penault-Llorca, F.; Mercier, O.; Commo, F.; Morat, L.; Sabatier, L.; Dartevelle, P.; Taranchon, E.; Besse, B.; et al. Differential expression of biomarkers in primary non-small cell lung cancer and metastatic sites. J. Thorac. Oncol. 2009, 4, 1212-1220. [CrossRef] [PubMed]

18. Hanibuchi, M.; Kim, S.-J.; Fidler, I.J.; Nishioka, Y. The molecular biology of lung cancer brain metastasis: an overview of current comprehensions and future perspectives. J. Med. Investig. JMI 2014, 61, 241-253. [CrossRef]

19. Mascaux, C.; Iannino, N.; Martin, B.; Paesmans, M.; Berghmans, T.; Dusart, M.; Haller, A.; Lothaire, P.; Meert, A.-P.; Noel, S.; et al. The role of RAS oncogene in survival of patients with lung cancer: A systematic review of the literature with meta-analysis. Br. J. Cancer 2005, 92, 131-139. [CrossRef] [PubMed]

20. Guibert, N.; Ilie, M.; Long, E.; Hofman, V.; Bouhlel, L.; Brest, P.; Mograbi, B.; Marquette, C.H.; Didier, A.; Mazieres, J.; et al. KRAS mutations in lung adenocarcinoma: Molecular and epidemiological characteristics, methods for detection, and therapeutic strategy perspectives. Curr. Mol. Med. 2015, 15, 418-432. [CrossRef] [PubMed]

21. Ramlau, R.; Cufer, T.; Berzinec, P.; Dziadziuszko, R.; Olszewski, W.; Popper, H.; Bajcic, P.; Dušek, L.; Zbozinkova, Z.; Pirker, R.; INSIGHT study team. Epidermal growth factor receptor mutation-positive non-small-cell lung cancer in the real-world setting in central Europe: The INSIGHT study. J. Thorac. Oncol. 2015, 10, 1370-1374. [CrossRef] [PubMed] 
22. Shin, D.-Y.; Na, I.I.; Kim, C.H.; Park, S.; Baek, H.; Yang, S.H. EGFR mutation and brain metastasis in pulmonary adenocarcinomas. J. Thorac. Oncol. 2014, 9, 195-199. [CrossRef] [PubMed]

23. Guan, J.; Chen, M.; Xiao, N.; Li, L.; Zhang, Y.; Li, Q.; Yang, M.; Liu, L.; Chen, L. EGFR mutations are associated with higher incidence of distant metastases and smaller tumor size in patients with non-small-cell lung cancer based on PET/CT scan. Med. Oncol. Northwood Lond. Engl. 2016, 33, 1. [CrossRef] [PubMed]

24. Baek, M.Y.; Ahn, H.K.; Park, K.R.; Park, H.-S.; Kang, S.M.; Park, I.; Kim, Y.S.; Hong, J.; Sym, S.J.; Park, J.; et al. Epidermal growth factor receptor mutation and pattern of brain metastasis in patients with non-small cell lung cancer. Korean J. Intern. Med. 2016, 20. [CrossRef] [PubMed]

25. Renaud, S.; Seitlinger, J.; Falcoz, P.-E.; Schaeffer, M.; Voegeli, A.-C.; Legrain, M.; Beau-Faller, M.; Massard, G. Specific KRAS amino acid substitutions and EGFR mutations predict site-specific recurrence and metastasis following non-small-cell lung cancer surgery. Br. J. Cancer 2016, 115, 346-353. [CrossRef] [PubMed]

26. Hendriks, L.E.L.; Smit, E.F.; Vosse, B.A.H.; Mellema, W.W.; Heideman, D.A.M.; Bootsma, G.P.; Westenend, M.; Pitz, C.; de Vries, G.J.; Houben, R.; et al. EGFR mutated non-small cell lung cancer patients: More prone to development of bone and brain metastases? Lung Cancer Amst. Neth. 2014, 84, 86-91. [CrossRef] [PubMed]

27. Li, B.T.; Lou, E.; Hsu, M.; Yu, H.A.; Naidoo, J.; Zauderer, M.G.; Sima, C.; Johnson, M.L.; Daras, M.; DeAngelis, L.M.; et al. Serum biomarkers associated with clinical outcomes fail to predict brain metastases in patients with stage IV non-small cell lung cancers. PLoS ONE 2016, 11, e0146063. [CrossRef] [PubMed]

28. Li, B.; Sun, S.-Z.; Yang, M.; Shi, J.-L.; Xu, W.; Wang, X.-F.; Song, M.-M.; Chen, H.-M. The correlation between EGFR mutation status and the risk of brain metastasis in patients with lung adenocarcinoma. J. Neurooncol. 2015, 124, 79-85. [CrossRef] [PubMed]

29. Rossi, S.; D’Argento, E.; Basso, M.; Strippoli, A.; Dadduzio, V.; Cerchiaro, E.; Martini, M.; Cassano, A.; Barone, C. Different EGFR gene mutations in Exon 18, 19 and 21 as prognostic and predictive markers in NSCLC: A single institution analysis. Mol. Diagn. Ther. 2016, 20, 55-63. [CrossRef] [PubMed]

30. Shin, S.M.; Cooper, B.T.; Chachoua, A.; Butler, J.; Donahue, B.; Silverman, J.S.; Kondziolka, D. Survival but not brain metastasis response relates to lung cancer mutation status after radiosurgery. J. Neurooncol. 2016, 126, 483-491. [CrossRef] [PubMed]

31. Li, H.; Zhang, X.; Cao, J.; Su, P.; Lian, J.; Song, X.; Yang, W.; Han, S.; Xi, Y.; Wang, Y. Exon 19 deletion of epidermal growth factor receptor is associated with prolonged survival in brain metastases from non-small-cell lung cancer. Tumour Biol. J. Int. Soc. Oncodevelopmental Biol. Med. 2015, 36, 9251-9258. [CrossRef] [PubMed]

32. Singh, S.; Trevino, J.; Bora-Singhal, N.; Coppola, D.; Haura, E.; Altiok, S.; Chellappan, S.P. EGFR/Src/Akt signaling modulates Sox2 expression and self-renewal of stem-like side-population cells in non-small cell lung cancer. Mol. Cancer 2012, 11, 73. [CrossRef] [PubMed]

33. Lopes, G.L.; Vattimo, E.F.D.Q.; Junior, G.D. Identifying activating mutations in the EGFR gene: Prognostic and therapeutic implications in non-small cell lung cancer. J. Bras. Pneumol. 2015, 41, 365-375. [CrossRef] [PubMed]

34. Wang, S.; Wang, Z. Meta-analysis of epidermal growth factor receptor and KRAS gene status between primary and corresponding metastatic tumours of non-small cell lung cancer. Clin. Oncol. 2015, 27, 30-39. [CrossRef] [PubMed]

35. Ballard, P.; Yates, J.W.; Yang, Z.; Kim, D.-W.; Yang, J.C.-H.; Cantarini, M.; Pickup, K.; Jordan, A.; Hickey, M.; Grist, M.; et al. Preclinical comparison of osimertinib with other EGFR-TKIs in EGFR-Mutant NSCLC Brain metastases models, and early evidence of clinical brain metastases activity. Clin. Cancer Res. 2016, 22, 5130-5140. [CrossRef]

36. Toyokawa, G.; Seto, T.; Takenoyama, M.; Ichinose, Y. Insights into brain metastasis in patients with ALK lung cancer: Is the brain truly a sanctuary? Cancer Metastasis Rev. 2015, 34, 797-805. [CrossRef] [PubMed]

37. Goldstraw, P.; Crowley, J.; Chansky, K.; Giroux, D.J.; Groome, P.A.; Rami-Porta, R.; Postmus, P.E.; Rusch, V.; Sobin, L. International Association for the Study of Lung Cancer International Staging Committee; Participating Institutions The IASLC Lung Cancer Staging Project: proposals for the revision of the TNM stage groupings in the forthcoming (seventh) edition of the TNM Classification of malignant tumours. J. Thorac. Oncol. 2007, 2, 706-714. [PubMed]

38. Eisenhauer, E.A.; Therasse, P.; Bogaerts, J.; Schwartz, L.H.; Sargent, D.; Ford, R.; Dancey, J.; Arbuck, S.; Gwyther, S.; Mooney, M.; et al. New response evaluation criteria in solid tumours: Revised RECIST guideline (version 1.1). Eur. J. Cancer Oxf. Engl. 2009, 45, 228-247. [CrossRef] [PubMed] 
39. Jacot, W.; Lopez-Crapez, E.; Thezenas, S.; Senal, R.; Fina, F.; Bibeau, F.; Romieu, G.; Lamy, P.-J. Lack of EGFR-activating mutations in European patients with triple-negative breast cancer could emphasise geographic and ethnic variations in breast cancer mutation profiles. Breast Cancer Res. BCR 2011, 13, R133. [CrossRef] [PubMed]

40. Masters, G.A.; Temin, S.; Azzoli, C.G.; Giaccone, G.; Baker, S.; Brahmer, J.R.; Ellis, P.M.; Gajra, A.; Rackear, N.; Schiller, J.H.; et al. American Society of Clinical Oncology Clinical Practice Systemic Therapy for Stage IV Non-Small-Cell Lung Cancer: American Society of Clinical Oncology Clinical Practice Guideline Update. J. Clin. Oncol. 2015, 33, 3488-3515. [CrossRef] [PubMed]

41. Reck, M.; Popat, S.; Reinmuth, N.; de Ruysscher, D.; Kerr, K.M.; Peters, S.; ESMO Guidelines Working Group. Metastatic non-small-cell lung cancer (NSCLC): ESMO Clinical Practice Guidelines for diagnosis, treatment and follow-up. Ann. Oncol. 2014, 25, iii27-iii39. [CrossRef] [PubMed]

42. Soffietti, R.; Cornu, P.; Delattre, J.Y.; Grant, R.; Graus, F.; Grisold, W.; Heimans, J.; Hildebrand, J.; Hoskin, P.; Kalljo, M.; et al. EFNS Guidelines on diagnosis and treatment of brain metastases: Report of an EFNS Task Force. Eur. J. Neurol. 2006, 13, 674-681. [CrossRef] [PubMed]

43. Le Rhun, É.; Dhermain, F.; Noël, G.; Reyns, N.; Carpentier, A.; Mandonnet, E.; Taillibert, S.; Metellus, P.; ANOCEF. 1'Association des neuro-oncologues d'expression franc,aise ANOCEF guidelines for the management of brain metastases. Cancer Radiothérapie J. Société Fr. Radiothérapie Oncol. 2015, 19, 66-71. [CrossRef] [PubMed]

(C) 2016 by the authors; licensee MDPI, Basel, Switzerland. This article is an open access article distributed under the terms and conditions of the Creative Commons Attribution (CC-BY) license (http://creativecommons.org/licenses/by/4.0/). 